\title{
R\&D Model of Platform Technology for Digital Content
}

\author{
Analysis Based on numerical simulation \\ Fujin Zhang, Jie Shang, Bin Wang \\ Department of Public Economics \\ Xiamen University \\ Xiamen, China \\ E-mail: ice-sun_0717@163.com
}

\begin{abstract}
This paper studies the related problems which belong to research of digital content platform by using numerical simulation. Results from the research show that: the Nash-equilibrium is not the optimal outcome in the $R \& D$ competition. The government should pay attention to the continuity of investment. The larger the conversion rate of the user scale, $R \& D$ investment allowance rate and the foresight of companies are, the more the technology stock and consumer welfare are.
\end{abstract}

Keywords-R\&D; Nash-equilibrium; digital content platform; numerical simulation

\section{INTRODUCTION}

Technology R\&D is new breed, new technology, new service, and the research staff or R\&D institution use proper ways and means with certain material to meet the market demand. The digital content platform is different from normal digital content productions, the quality of normal digital content productions is depend on $R \& D$ input at this time, it doesn't have the natural inheritance of input and quality. But the R\&D of digital content platform has constancy, every period input would affect the final production quality and technical level, the provider of digital content platform needs continually input to fine down the older version and get newer or higher version production, and in this progress no or just a few users would switch.

Technical research of digital content platform decides its mode of expression and affects the value gained by the users. As the quality development of digital content platform, one side it needs depend on flexible application of existing digital technique, the other side it needs weeds bring forth new from the original knowledge ,and carry out research of new digital technique. Only continues improving the digital technique, the digital content platform could continue gets technical support and gains new means of expression, the creation of digital content could get richer, the users could get more value.

So the enterprises in free market would take the technical R\&D by themselves, and continues this process? Can outstanding technique defeat the poor one, achieve survival of the fittest and technical innovation, or have the possibility of subprime technology captures market? Is there having one optimal or balanced technical R\&D Input? All of these problems, we will discuss in the following and seek the answer through numerical simulation.

\section{MATHEMATICAL MODEL}

\section{A. Description of Consumer Behavior}

Supposing that there have $N$ consumers on the market, there is a factor which can affect consumer decision defined as horizontal differentiation coefficient $h$ 。 Horizontal differentiation coefficient of Consumer is determined by (1).

$$
h_{i}=(i-1) /(N-1)
$$

And supposing that the consumer decision only affected by high-tech stock, network externality, horizontal differentiation coefficient, so the utility of consumer $i$ at the period $t$ is determined by (2).

$$
v_{i j, t}=k\left(1-\left|h_{i}-H_{j}\right|\right) T_{j, t} D_{j, t-1}^{\mu}
$$

In this formula, $H_{j}$ means the located position of $j$ th digital content platform in the horizontal differentiation coefficient space, which is fixed. $T_{j, t}$ means the technical stock of jth digital content platform at period t. $D_{j, t-1}$ means consumer scale of digital content platform $\mathrm{j}$ at $\mathrm{t}$-1period, which also is the original consumer scale of platform $j$ at $t$ period. $\mu$ is the factor of network externality when the consumer are making decision, $\mu$ is larger , the effect is more high.

In the $\mathrm{R} \& \mathrm{D}$ process, the enterprises' input is continuous, so the technical stock $T_{j, t}$ of digital content platform is determined by (3)

$$
T_{j, t}=T_{j, t-1}+R_{j, t}^{\rho}
$$

In this formula, $R_{j, t}$ is the technical $\mathrm{R} \& \mathrm{D}$ Input of digital content platform j at period t. $\rho$ is transforming factor from input to technical stock, when $\rho$ is above 1,the marginal output of technical stock increases progressively. When $\rho=1$, there exists linear correlation between technical R\&D and technical stock, and when $\rho<1$, that means the marginal output decrease from the technical $R \& D$ to technical stock . 
There must are new technical followers with certain probability $\alpha$ in consumers. Compared to the intelligent consumers who have taken adaptive expectations, new technical followers don't treat the present scale of newer or older technique as the basis of utility evaluation. They keep an eye on the market, and optimistically think the market would be survival of the fittest. As the time past, the new technique would defeat the older one, and occupy all the market. So they are willing to be forerunner. For the new technical followers, whatever the how big the network size is, new technique is the best choice forever.

\section{B. Description of Enterprise's Behavior}

The market is oligopoly market composed by two enterprises which provide digital content platform, and the location $H_{j}(j=1,2)$ in the level difference coefficient, the original technical stock and consumers' network size are fixed. The enterprises decide the technical $R \& D$ funds to optimize the utility at each period. Though the enterprise could obtain income through many ways, for the need of simplification, we suppose the income of enterprises depend on the market share. So we can set the profit of digital content platform $j$ at $t$ period as in

$$
\pi_{j, t}=a D_{j, t}-(1-s) R_{j, t}
$$

The profit of enterprise at $t$ period is actually in proportion to consumers' network size at period t, $a$ means transformation ratio(In this study, we set $a$ of two platforms is the same). $s$ means the subsidy applied by the government to assist the $\mathrm{R} \& \mathrm{D}$, when $s=0$,the enterprises undertake the all cost.

The enterprise $\mathrm{j}$ decides technical $\mathrm{R} \& \mathrm{D}$ input at each period based on maximum profit at period $\mathrm{k}$ by (5).

$$
\operatorname{Max} \sum_{t=k}^{k+n-1} \lambda^{t-k} \pi_{j, t}
$$

Where $\lambda$ is discount rate, $\lambda$ is determined by the enterprise's attitude to present and long term profit. In this study, we suppose $\lambda$ is fixed.

When $n=1$, the enterprise $\mathrm{j}$ is very nearsightedness, it only consider to obtain the biggest profit at $\mathrm{k}$ period. When $n \geq 2$, the enterprise $\mathrm{j}$ is foresight, who not only consider the profit at period $k+1$, but also consider the profit at period $k+n-1$.

\section{ANALYSIS BASED ON NUMERICAL SIMULATION}

\section{A. Take a decision by turns, $R \& D$ and Nash-equinlibrium}

Supposing that the companies take a decision by turns: At the first stage, company 2 which has the new technique carries out the policy of R\&D input to make the maximize profit. At the second stage, the incumbent (company 1) in the market carries out the policy of R\&D input to make the maximize profit. At the third stage, company 2 carries out the policy as first stage based on the current market condition. At fourth stage, company 1 carries out the policy as second stage based on the current market condition. And at the fifth stage, company 2 should ...Repeat this to infinite.
Set $N=1001, \alpha=0.02$ and create one random group of consumer. Given the values of parameters as $H_{1}=0.25$, $H_{2}=0.75, T_{1,0}=10, T_{2,0}=15, D_{1,0}=900, a=0.1, \lambda=0.95$ , $\rho=0.5, s=0$ and $n=5$, Make $D_{2,0}$ changing from 0 to 100 , each step is 50 . The evolution path of the market under each $D_{2,0}$ is shown in Table 1-5.

TABLE I. The EVOLUTION PATH OF THE MARKet $\left(D_{2,0}=0\right)$

\begin{tabular}{|c|c|c|c|c|c|c|c|c|}
\hline$t$ & $R_{1, t}$ & $R_{2, t}$ & $T_{1, t}$ & $T_{2, t}$ & $D_{1, t}$ & $D_{2, t}$ & $\pi_{1, t}$ & $\pi_{2, t}$ \\
\hline 1 & 0 & 30 & 10.0 & 20.5 & 984 & 17 & 98.4 & -28.3 \\
\hline 2 & 10 & 30 & 13.2 & 26.0 & 984 & 17 & 88.4 & -28.3 \\
\hline 3 & 10 & 0 & 16.3 & 26.0 & 984 & 17 & 88.4 & 1.7 \\
\hline 4 & 0 & 0 & 16.3 & 26.0 & 984 & 17 & 98.4 & 1.7 \\
\hline 5 & 0 & 0 & 16.3 & 26.0 & 984 & 17 & 98.4 & 1.7 \\
\hline 6 & 0 & 0 & 16.3 & 26.0 & 984 & 17 & 98.4 & 1.7 \\
\hline 7 & 0 & 0 & 16.3 & 26.0 & 984 & 17 & 98.4 & 1.7 \\
\hline 8 & 0 & 0 & 16.3 & 26.0 & 984 & 17 & 98.4 & 1.7 \\
\hline 9 & 0 & 0 & 16.3 & 26.0 & 984 & 17 & 98.4 & 1.7 \\
\hline 10 & 0 & 0 & 16.3 & 26.0 & 984 & 17 & 98.4 & 1.7 \\
\hline 11 & 0 & 0 & 16.3 & 26.0 & 984 & 17 & 98.4 & 1.7 \\
\hline 12 & 0 & 0 & 16.3 & 26.0 & 984 & 17 & 98.4 & 1.7 \\
\hline 13 & 0 & 0 & 16.3 & 26.0 & 984 & 17 & 98.4 & 1.7 \\
\hline 14 & 0 & 0 & 16.3 & 26.0 & 984 & 17 & 98.4 & 1.7 \\
\hline 15 & 0 & 0 & 16.3 & 26.0 & 984 & 17 & 98.4 & 1.7 \\
\hline 16 & 0 & 0 & 16.3 & 26.0 & 984 & 17 & 98.4 & 1.7 \\
\hline 17 & 0 & 0 & 16.3 & 26.0 & 984 & 17 & 98.4 & 1.7 \\
\hline 18 & 0 & 0 & 16.3 & 26.0 & 984 & 17 & 98.4 & 1.7 \\
\hline 19 & 0 & 0 & 16.3 & 26.0 & 984 & 17 & 98.4 & 1.7 \\
\hline 20 & 0 & 0 & 16.3 & 26.0 & 984 & 17 & 98.4 & 1.7 \\
\hline
\end{tabular}

TABLE II. The EVOLUtion PATH OF The MARKet $\left(D_{2,0}=25\right.$ )

\begin{tabular}{|c|l|l|l|l|l|l|l|l|}
\hline$t$ & $R_{1, t}$ & $R_{2, t}$ & $T_{1, t}$ & $T_{2, t}$ & $D_{1, t}$ & $D_{2, t}$ & $\pi_{1, t}$ & $\pi_{2, t}$ \\
\hline 1 & 0 & 30 & 10.0 & 20.5 & 974 & 27 & 97.4 & -27.3 \\
\hline 2 & 10 & 30 & 13.2 & 26.0 & 984 & 17 & 88.4 & -28.3 \\
\hline 3 & 10 & 0 & 16.3 & 26.0 & 984 & 17 & 88.4 & 1.7 \\
\hline 4 & 0 & 0 & 16.3 & 26.0 & 984 & 17 & 98.4 & 1.7 \\
\hline 5 & 0 & 0 & 16.3 & 26.0 & 984 & 17 & 98.4 & 1.7 \\
\hline 6 & 0 & 0 & 16.3 & 26.0 & 984 & 17 & 98.4 & 1.7 \\
\hline 7 & 0 & 0 & 16.3 & 26.0 & 984 & 17 & 98.4 & 1.7 \\
\hline 8 & 0 & 0 & 16.3 & 26.0 & 984 & 17 & 98.4 & 1.7 \\
\hline 9 & 0 & 0 & 16.3 & 26.0 & 984 & 17 & 98.4 & 1.7 \\
\hline 10 & 0 & 0 & 16.3 & 26.0 & 984 & 17 & 98.4 & 1.7 \\
\hline 11 & 0 & 0 & 16.3 & 26.0 & 984 & 17 & 98.4 & 1.7 \\
\hline 12 & 0 & 0 & 16.3 & 26.0 & 984 & 17 & 98.4 & 1.7 \\
\hline 13 & 0 & 0 & 16.3 & 26.0 & 984 & 17 & 98.4 & 1.7 \\
\hline 14 & 0 & 0 & 16.3 & 26.0 & 984 & 17 & 98.4 & 1.7 \\
\hline 15 & 0 & 0 & 16.3 & 26.0 & 984 & 17 & 98.4 & 1.7 \\
\hline 16 & 0 & 0 & 16.3 & 26.0 & 984 & 17 & 98.4 & 1.7 \\
\hline 17 & 0 & 0 & 16.3 & 26.0 & 984 & 17 & 98.4 & 1.7 \\
\hline 18 & 0 & 0 & 16.3 & 26.0 & 984 & 17 & 98.4 & 1.7 \\
\hline 19 & 0 & 0 & 16.3 & 26.0 & 984 & 17 & 98.4 & 1.7 \\
\hline 20 & 0 & 0 & 16.3 & 26.0 & 984 & 17 & 98.4 & 1.7 \\
\hline
\end{tabular}

TABLE III. The EVolution PAth of the Market $\left(D_{2,0}=50\right)$

\begin{tabular}{|c|c|c|c|c|c|c|c|c|}
\hline$t$ & $R_{1, t}$ & $R_{2, t}$ & $T_{1, t}$ & $T_{2, t}$ & $D_{1, t}$ & $D_{2, t}$ & $\pi_{1, t}$ & $\pi_{2, t}$ \\
\hline 1 & 0 & 10 & 10.0 & 18.2 & 861 & 140 & 86.1 & 4.0 \\
\hline 2 & 20 & 10 & 14.5 & 21.3 & 679 & 322 & 47.9 & 22.2 \\
\hline 3 & 20 & 10 & 18.9 & 24.5 & 535 & 466 & 33.5 & 36.6 \\
\hline 4 & 10 & 10 & 22.1 & 27.6 & 436 & 565 & 33.6 & 46.5 \\
\hline 5 & 10 & 20 & 25.3 & 32.1 & 357 & 644 & 25.7 & 44.4 \\
\hline
\end{tabular}




\begin{tabular}{|c|c|c|c|c|c|c|c|c|}
\hline 6 & 20 & 20 & 29.7 & 36.6 & 310 & 691 & 11.0 & 49.1 \\
\hline 7 & 20 & 10 & 34.2 & 39.8 & 293 & 708 & 9.3 & 60.8 \\
\hline 8 & 10 & 10 & 37.4 & 42.9 & 284 & 717 & 18.4 & 61.7 \\
\hline 9 & 10 & 20 & 40.5 & 47.4 & 271 & 730 & 17.1 & 53.0 \\
\hline 10 & 20 & 20 & 45.0 & 51.9 & 265 & 736 & 6.5 & 53.6 \\
\hline 11 & 20 & 10 & 49.5 & 55.0 & 272 & 729 & 7.2 & 62.9 \\
\hline 12 & 10 & 10 & 52.6 & 58.2 & 280 & 721 & 18.0 & 62.1 \\
\hline 13 & 10 & 10 & 55.8 & 61.3 & 288 & 713 & 18.8 & 61.3 \\
\hline 14 & 10 & 10 & 59.0 & 64.5 & 296 & 705 & 19.6 & 60.5 \\
\hline 15 & 10 & 10 & 62.1 & 67.7 & 304 & 697 & 20.4 & 59.7 \\
\hline 16 & 10 & 10 & 65.3 & 70.8 & 312 & 689 & 21.2 & 58.9 \\
\hline 17 & 10 & 10 & 68.5 & 74.0 & 320 & 681 & 22.0 & 58.1 \\
\hline 18 & 10 & 10 & 71.6 & 77.2 & 328 & 673 & 22.8 & 57.3 \\
\hline 19 & 10 & 10 & 74.8 & 80.3 & 335 & 666 & 23.5 & 56.6 \\
\hline 20 & 0 & 10 & 74.8 & 83.5 & 327 & 674 & 32.7 & 57.4 \\
\hline
\end{tabular}

TABle IV. The EVOlution Path of the MARKet $\left(D_{2,0}=75\right.$ )

\begin{tabular}{|c|c|c|c|c|c|c|c|c|}
\hline$t$ & $R_{1, t}$ & $R_{2, t}$ & $T_{1, t}$ & $T_{2, t}$ & $D_{1, t}$ & $D_{2, t}$ & $\pi_{1, t}$ & $\pi_{2, t}$ \\
\hline 1 & 0 & 10 & 10.0 & 18.2 & 722 & 279 & 72.2 & 17.9 \\
\hline 2 & 20 & 10 & 14.5 & 21.3 & 524 & 477 & 32.4 & 37.7 \\
\hline 3 & 20 & 10 & 18.9 & 24.5 & 415 & 586 & 21.5 & 48.6 \\
\hline 4 & 10 & 10 & 22.1 & 27.6 & 348 & 653 & 24.8 & 55.3 \\
\hline 5 & 10 & 20 & 25.3 & 32.1 & 292 & 709 & 19.2 & 50.9 \\
\hline 6 & 0 & 20 & 25.3 & 36.6 & 146 & 855 & 14.6 & 65.5 \\
\hline 7 & 0 & 0 & 25.3 & 36.6 & 0 & 1001 & 0.0 & 100.1 \\
\hline 8 & 0 & 0 & 25.3 & 36.6 & 0 & 1001 & 0.0 & 100.1 \\
\hline 9 & 0 & 0 & 25.3 & 36.6 & 0 & 1001 & 0.0 & 100.1 \\
\hline 10 & 0 & 0 & 25.3 & 36.6 & 0 & 1001 & 0.0 & 100.1 \\
\hline 11 & 0 & 0 & 25.3 & 36.6 & 0 & 1001 & 0.0 & 100.1 \\
\hline 12 & 0 & 0 & 25.3 & 36.6 & 0 & 1001 & 0.0 & 100.1 \\
\hline 13 & 0 & 0 & 25.3 & 36.6 & 0 & 1001 & 0.0 & 100.1 \\
\hline 14 & 0 & 0 & 25.3 & 36.6 & 0 & 1001 & 0.0 & 100.1 \\
\hline 15 & 0 & 0 & 25.3 & 36.6 & 0 & 1001 & 0.0 & 100.1 \\
\hline 16 & 0 & 0 & 25.3 & 36.6 & 0 & 1001 & 0.0 & 100.1 \\
\hline 17 & 0 & 0 & 25.3 & 36.6 & 0 & 1001 & 0.0 & 100.1 \\
\hline 18 & 0 & 0 & 25.3 & 36.6 & 0 & 1001 & 0.0 & 100.1 \\
\hline 19 & 0 & 0 & 25.3 & 36.6 & 0 & 1001 & 0.0 & 100.1 \\
\hline 20 & 0 & 0 & 25.3 & 36.6 & 0 & 1001 & 0.0 & 100.1 \\
\hline
\end{tabular}

TABle V. The eVolution path of the market $\left(D_{2,0}=100\right)$

\begin{tabular}{|c|c|c|c|c|c|c|c|c|}
\hline$t$ & $R_{1, t}$ & $R_{2, t}$ & $T_{1, t}$ & $T_{2, t}$ & $D_{1, t}$ & $D_{2, t}$ & $\pi_{1, t}$ & $\pi_{2, t}$ \\
\hline 1 & 0 & 10 & 10.0 & 18.2 & 673 & 328 & 67.3 & 22.8 \\
\hline 2 & 20 & 10 & 14.5 & 21.3 & 483 & 518 & 28.3 & 41.8 \\
\hline 3 & 20 & 10 & 18.9 & 24.5 & 386 & 615 & 18.6 & 51.5 \\
\hline 4 & 10 & 10 & 22.1 & 27.6 & 326 & 675 & 22.6 & 57.5 \\
\hline 5 & 10 & 20 & 25.3 & 32.1 & 277 & 724 & 17.7 & 52.4 \\
\hline 6 & 0 & 20 & 25.3 & 36.6 & 122 & 879 & 12.2 & 67.9 \\
\hline 7 & 0 & 0 & 25.3 & 36.6 & 0 & 1001 & 0.0 & 100.1 \\
\hline 8 & 0 & 0 & 25.3 & 36.6 & 0 & 1001 & 0.0 & 100.1 \\
\hline 9 & 0 & 0 & 25.3 & 36.6 & 0 & 1001 & 0.0 & 100.1 \\
\hline 10 & 0 & 0 & 25.3 & 36.6 & 0 & 1001 & 0.0 & 100.1 \\
\hline 11 & 0 & 0 & 25.3 & 36.6 & 0 & 1001 & 0.0 & 100.1 \\
\hline 12 & 0 & 0 & 25.3 & 36.6 & 0 & 1001 & 0.0 & 100.1 \\
\hline 13 & 0 & 0 & 25.3 & 36.6 & 0 & 1001 & 0.0 & 100.1 \\
\hline 14 & 0 & 0 & 25.3 & 36.6 & 0 & 1001 & 0.0 & 100.1 \\
\hline 15 & 0 & 0 & 25.3 & 36.6 & 0 & 1001 & 0.0 & 100.1 \\
\hline 16 & 0 & 0 & 25.3 & 36.6 & 0 & 1001 & 0.0 & 100.1 \\
\hline 17 & 0 & 0 & 25.3 & 36.6 & 0 & 1001 & 0.0 & 100.1 \\
\hline 18 & 0 & 0 & 25.3 & 36.6 & 0 & 1001 & 0.0 & 100.1 \\
\hline 19 & 0 & 0 & 25.3 & 36.6 & 0 & 1001 & 0.0 & 100.1 \\
\hline 20 & 0 & 0 & 25.3 & 36.6 & 0 & 1001 & 0.0 & 100.1 \\
\hline
\end{tabular}

From above tables, we can obtain some conclusions. Firstly, Affected by network externality, non-superior technology might capture the market, according to Table I and Table II. Though the platform 2 enters markets with new technique, it is still suppressed by the platform 1 and gets negligible consumer scale. Secondly, as the original consumer scale of platform $2\left(D_{2,0}\right)$ increasing, platform 2 would get higher competitiveness of technology at original state. Platform 2 can benefit from this kind of technological competitiveness, shown by Table I to Table V. Platform 2 attracts more consumers and finally occupies the whole market in Table IV and Table V. Please note, from the side of original state, the increasing of $D_{2,0}$ indeed improves the market competition of platform 2, but from the whole market, the increasing of $D_{2,0}$ may not be good for the platform 2 . Because the development of original market competition of platform 2 may let the platform 1 early make a decision to carry out large-scale technical $R \& D$ input, bridge the gap between the both platforms finally and make platform 2 lose the technological superiority. Thirdly, the technical compete between the platforms isn't endless. When one of the platforms find that there's no profit through research and development, it would give up investment. And if both the two platform give up the technical $R \& D$, it will appear a stable state, this can be shown in Table I II III IV and V. And this state is called Nash equilibrium.

We draw the optimal reaction curve at stable state of Table I in Figure 1.

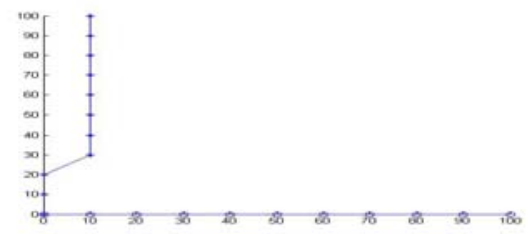

Figure 1. Nash-equilibrium $\left(D_{2,0}=0\right)$

According to Figure 1, the optimal curve of both platforms' technical R\&D input intersects at point $(0,0)$ after 3 periods; this is the Nash equilibrium which we are finding. At this point, both of the platforms' technical level remains stagnant and the other variables stay the same, it can make the Nash equilibrium last forever. The optimal reaction curve of performs in Table II, IV and V is same with Table I, they also intersect at the point $(0,0)$ and reach the stable state finally.

The Nash equilibrium which was shown above is not a reasonable state of market. Oppositely, this state should be prevented or intervened. Fortunately, not all the competition results intersect at the point $(0,0)$. According to Table III, there has the possibility that the technical R\&Q competition will be continuous. We draw out the related optimal reaction curve in Figure 2 as follows.

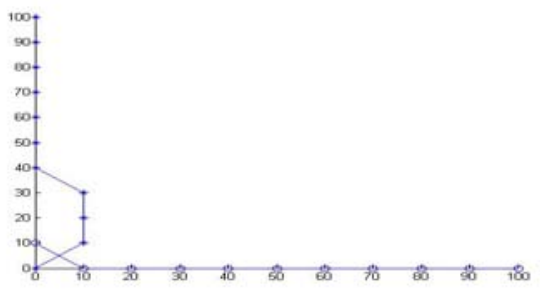

Figure 2. Nash-equilibrium $\left(D_{2,0}=50\right)$ 
From Table III and Figure 2, we could find that both of the platforms get high technology stock $\left(T_{1,20}=74.9, T_{2,20}=83.5\right)$ after 20 periods. Even so, the two optimal reaction curves still do not intersect each other. This means the technology competition would last continually in this kind of market state. This state is far better than the market state corresponding to Table I II IV and V. The policies of the government is not to make the market reaching Nash equilibrium of $(0,0)$, the government should lead platforms' continued investment.

\section{B. The Factors effecting $R \& D$ input}

Given $N=1001 \alpha=0.02 H_{1}=0.25 H_{2}=0.75 T_{1,0}=10$, $T_{2,0}=15 D_{1,0}=900 a=0.2 \lambda=0.95 \rho=0.5 s=0 \quad n=5$, we make $D_{2,0}$ changing from 0 to 100 with step 25. Based on the basic simulation, changing some factors, we carry out 3 simulations as follows.

Changing the transformation ratio $\alpha$ from 0.05 to 0.4 with step 0.05 , we repeat the basic simulation keeping the other parameters same and record the market path.

Record the technology stock $\left(T_{1,20}, T_{2,20}\right)$ in Table VI. At the same time, we mark the market state with grey when technical R\&D input reaches Nash-equilibrium $(0,0)$ and the unmarked ones mean the technical R\&D input is continuous at 21th period.

TABLE VI. THE TECHNOLOGY STOCK WITH DIFFERENT $\alpha$

\begin{tabular}{|c|c|c|c|c|}
\hline$D_{2,0}$ & 0 & 25 & 75 & 100 \\
\hline 0.05 & $(10.0,15.0)$ & $(10.0,15.0)$ & $(10.0,21.3)$ & $(35.3,34.0)$ \\
\hline 0.1 & $(16.3,26.0)$ & $(16.3,26.0)$ & $(25.3,36.6)$ & $(25.3,36.6)$ \\
\hline 0.15 & $(16.3,26.0)$ & $(22.6,27.6)$ & $(82.6,86.1)$ & $(81.6,85.5)$ \\
\hline 0.2 & $(41.6,90.9)$ & $(22.6,27.6)$ & $(92.1,88.1)$ & $(90.8,94.4)$ \\
\hline 0.25 & $(41.6,92.1)$ & $(27.9,29.1)$ & $(96.7,101.6)$ & $(102.4,97.6)$ \\
\hline 0.3 & $(41.6,92.1)$ & $(27.9,29.1)$ & $(101.0,106.3)$ & $(101.0,106.3)$ \\
\hline 0.35 & $(41.6,92.1)$ & $(112.5,114.9)$ & $(113.1,115.3)$ & $(114.8,118.3)$ \\
\hline 0.4 & $(41.6,93.3)$ & $(118.4,120.7)$ & $(122.5,127.5)$ & $(117.2,121.0)$ \\
\hline
\end{tabular}

Changing the value of $s$ from 0 to 0.7 with the step 0.25 , we repeat the basic simulation and record the market path. Record the technology stock $\left(T_{1,20}, T_{2,20}\right)$ in Table VII.

TABLE VII. THE TECHNOLOGY STOCK WITH DIFFERENT $S$

\begin{tabular}{|c|c|c|c|c|}
\hline$D_{2,0}$ & 0 & 25 & 75 & 100 \\
\hline 0 & $(10.0,15.0)$ & $(10.0,15.0)$ & $(10.0,21.3)$ & $(35.3,34.0)$ \\
\hline 0.25 & $(10.0,15.0)$ & $(16.3,26.0)$ & $(50.6,46.6)$ & $(31.6,42.9)$ \\
\hline 0.5 & $(16.3,26.0)$ & $(16.3,26.0)$ & $(25.3,36.6)$ & $(25.3,36.6)$ \\
\hline 0.75 & $(41.6,90.9)$ & $(22.6,27.6)$ & $(92.1,88.1)$ & $(90.8,94.4)$ \\
\hline
\end{tabular}

Changing the value of $s$ from 5 to 1 with the step 4, we repeat the basic simulation and record the market path. Record the technology stock $\left(T_{1,20}, T_{2,20}\right)$ in Table VII.
TABLE VIII. THE TECHNOLOGY STOCK WITH DIFFERENT $n$

\begin{tabular}{|c|c|c|c|c|}
\hline$D_{2,0}$ & 0 & 25 & 75 & 100 \\
\hline 5 & $(41.6,90.9)$ & $(22.6,27.6)$ & $(92.1,88.1)$ & $(90.8,94.4)$ \\
\hline 1 & $(10.0,15.0)$ & $(10.0,15.0)$ & $(22.6,34.0)$ & $(31.6,34.0)$ \\
\hline
\end{tabular}

As the increasing of $\alpha, s, n$, cells marked with grey shade incline to decrease, this means the possibility of the sustainable technical R\&D input when the market iterates after 20 periods is lager. We also find that the maximum values in each line incline to increase. This means it increases the technical R\&D input of both platforms from 1st to 20th period.

\section{CONCLUSION}

This paper studies the related problems which belong to research of digital content platform by using numerical simulation. Results from the research show that: the Nashequilibrium is not the optimal outcome in the $R \& D$ competition. The government should pay attention to the continuity of investment. The larger the conversion rate of the user scale, $R \& D$ investment allowance rate and the foresight of companies are, the more the technology stock and consumer welfare are.

\section{ACKNOWLEDGMENT}

Fujian province soft project (2012R0082) is sponsor.

\section{REFERENCES}

[1] Falvey. R., Foster.N. and Greenaway.D.”Intellectual Property Rights and Economic Growth". Review of Development Economics, 2006,10,(4):700-719.

[2] Yong Gyu Joo, So Young Sohn.”Structural equation model for effective CRM of digital content industry". Expert Systems with Applications,2008,(34):63-71.

[3] Paula M C Swatman,Cornelia Krueger, Kornelia van der Beek.”The changing digital content landscape: An evaluation of e-business model development in European online news and music”. Internet Research,2006:53-80.

[4] Cristina Mussinelli. "Digital Generation: Overview of Cultural and Entertainment Content Usage in Italy”. Pub Res Q,2009,(25):94-100.

[5] D.O. Choi and J.E. Oh ."Efficiency Analysis of the Digital Content Industry in Korea: An Application of Order-m Frontier Model”. Productivity, Efficiency, and Economic Growth in the Asia-Pacific Region,2009:299-314.

[6] Luca Lambertini,Raimondello Orsini.”Process and product innovation in a vertically differentiated monopoly". Economics Letters, 2000,(68):333-337.

[7] Pio Baake,Anette Boom.”Vertical product differentiation,network externalities,and compatibility decision". International Journal of Industrial Organization,2001,(19):267-284.

[8] Bing Jing."Network externalities and market segmentation in a monopoly”. Economics Letters, 2007,(95):7-13

[9] Banerjee, D. S.Lobbying and Commercial Software Piracy. European Journal of Political Economy, 2006,22,(1):139-155.

[10] Michael Wolf, Clint Wheelock. “Digital content unleashed”. Journal of Digital Asset Management, 2007,3(5):247-258. 